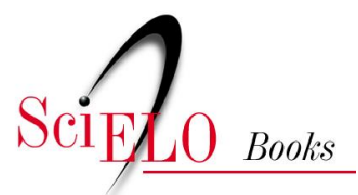

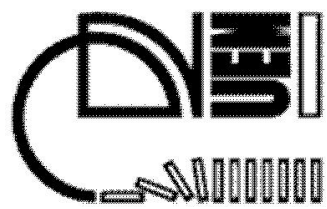

\title{
6 A história do Oeste Paranaense
}

\author{
Angelo Priori \\ Luciana Regina Pomari \\ Silvia Maria Amâncio \\ Veronica Karina Ipólito
}

PRIORI, A., et al. História do Paraná: séculos XIX e XX [online]. Maringá: Eduem, 2012. A história do Oeste Paranaense. pp. 75-89. ISBN 978-85-7628-587-8. Available from SciELO Books $<\underline{\text { http://books.scielo.org }>\text {. }}$

\section{(9)(1)(2)}

All the contents of this chapter, except where otherwise noted, is licensed under a Creative Commons Attribution-Non Commercial-ShareAlike 3.0 Unported.

Todo o conteúdo deste capítulo, exceto quando houver ressalva, é publicado sob a licença Creative Commons Atribuição Uso Não Comercial - Partilha nos Mesmos Termos 3.0 Não adaptada.

Todo el contenido de este capítulo, excepto donde se indique lo contrario, está bajo licencia de la licencia Creative Commons Reconocimento-NoComercial-CompartirIgual 3.0 Unported. 


\section{6}

\section{A história do Oeste Paranaense}

\section{Introdução}

O Oeste do Paraná, compreendido entre as microrregiões de Toledo, Foz do Iguaçu e Cascavel, já foi ocupado por indígenas, espanhóis, pertenceu à Capitania de São Paulo, formou o Território Federal do Iguaçu. O território foi anexo ao Brasil após vários tratados com a Espanha, passando então a pertencer à província de São Paulo. Em 1853 conseguiu sua emancipação política. Após se tornar parte integrante da Província do Paraná, acomodou imigrantes europeus, sobretudo eslavos, poloneses, ucranianos, alemães e italianos.

A área já era conhecida desde a primeira metade do século XVI, quando Dom Alvar Nunes Cabeza de Vaca percorreu, juntamente com indígenas e europeus, o território paranaense de Leste a Oeste, em direção ao Paraguai, onde assumiu o governo em nome do rei da Espanha.

Podemos dizer que o processo da ocupação da região Oeste ocorreu em quatro etapas. A primeira, e mais antiga, decorre da ocupação pelos índios que se espalhavam também por todo o território do continente sul-americano. A presença desses grupos indígenas, como Xetá, Kaigang e Guarani, foi notada no processo mais recente da colonização, fazendo com que essa população fosse mais uma vez reprimida. A segunda fase 
corresponde à atuação e presença dos padres jesuítas espanhóis que desenvolveram várias reduções (missões) pelo território. Esses aldeamentos indígenas, apesar de destruídos na primeira metade do século XVII pelos bandeirantes paulistas, conservaram forte a presença espanhola na região. A terceira etapa data do período entre 1881 e 1930, que corresponde à introdução do sistema das Obrages ${ }^{6}$, entre Foz do Iguaçu e Guaíra, cujo objetivo principal era a exploração extrativista da erva-mate e da madeira. Por último, a quarta fase ou a etapa recente aconteceu principalmente pela atuação das empresas colonizadoras que efetivaram a colonização moderna do Oeste paranaense.

A exemplo de outras regiões paranaenses, a ocupação de novas terras pelas populações brancas, tanto europeias quanto brasileiras, ocorreu, sobrepondo territórios nativos. Em fins do século XIX os espanhóis extraíam a erva-mate do Paraná e a exportavam para a Argentina e o Uruguai. Os obrageros controlavam alguns trabalhadores que contrabandeavam a erva-mate nos portos clandestinos situados às margens do Rio Paraná (GREGORY, 2002).

No início do século XX ocorreu na região um significativo aumento demográfico. A população de 126.977 pessoas aumentou para 685.711 habitantes. A elevação demográfica pode ser explicada pela modificação da estrutura da população, sobretudo com o incremento de mais de 100 mil imigrantes que vieram para o Paraná, acrescentando características diferenciadas à população. Outro fator que explica esse aumento demográfico foi o deslocamento de pessoas que chegavam de outras regiões do país, sobretudo de Santa Catarina e do Rio Grande do Sul.

$\mathrm{Na}$ década de 1920, houve uma entrada significativa de imigrantes alemães e italianos, que se dirigiam principalmente para o Oeste paranaense e se estabeleceram em pequenas propriedades familiares rurais, modelo de ocupação semelhante ao realizado em

6 Grandes áreas de terras concedidas pelo governo brasileiro a algumas empresas do exterior (argentinas e inglesas) para a extração de erva-mate e madeira no Oeste do Paraná (WACHOWICZ, 1987). 
Santa Catarina e Rio Grande do Sul (NADALIN, 2001). Na década de 1930, com o movimento denominado de 'marcha para o oeste', o governo brasileiro incentivou a migração para a ocupação de terras fronteiriças e do interior do país.

Construiu-se a concepção de 'vazio demográfico', quase despovoado, que deveria ser ocupado pela colonização pioneira. Essa ideia teve grandes repercussões entre pesquisadores que analisaram a história da região. Historiadores, geógrafos, sociólogos, representantes políticos, integrantes de órgãos de colonização eternizaram a visão do 'vazio demográfico' em livros e materiais de divulgação. Essa versão repetiu-se nos livros didáticos, importantes mecanismos de normatização de ideias na época, utilizando, principalmente, termos como 'sertão', 'terras devolutas', 'mata virgem' ou 'boca do sertão' (MOTA, 2005).

Wilson Martins, em sua obra Um Brasil diferente, publicada nos anos de 1950, retoma a emancipação política do Paraná em 1853, para afirmar que a preocupação do Presidente Zacarias de Góes e Vasconcelos era o povoamento dessa região.

\footnotetext{
A província era nesse momento, do ponto de vista humano, um ilimitado deserto, interrompido irregularmente por dezenove pequenos oásis, situados a distâncias imensas um dos outros - e distâncias literalmente intransponíveis [...]. Em compensação, na maior parte do território o vazio era absoluto: eram os 'campos gerais', era a floresta, era a Serra do Mar (MARTINS, 1995, p. 71, grifo nosso).
}

Essa interpretação é encontrada em muitas obras que trataram da ocupação e colonização do território paranaense. A expressão 'vazio demográfico' tornou-se ponto inicial para abordar o sistema de colonização da região a partir dos anos de 1930. No entanto, essa versão ignora a existência de populações tradicionais em todas as regiões do Paraná (MOTA, 2005). 


\section{Ocupação e colonização}

Até as duas primeiras décadas do século $\mathrm{XX}$ algumas regiões do Paraná ainda não haviam se integrado aos centros de decisão política e econômica do Estado. A conquista e ocupação de novas terras no Oeste do Estado começaram a tomar amplas dimensões no início da década de 1940, sob a perspectiva da busca do desenvolvimento e progresso do país, fomentada, sobretudo, no ideal politizado da 'marcha para o oeste' no governo de Getúlio Vargas.

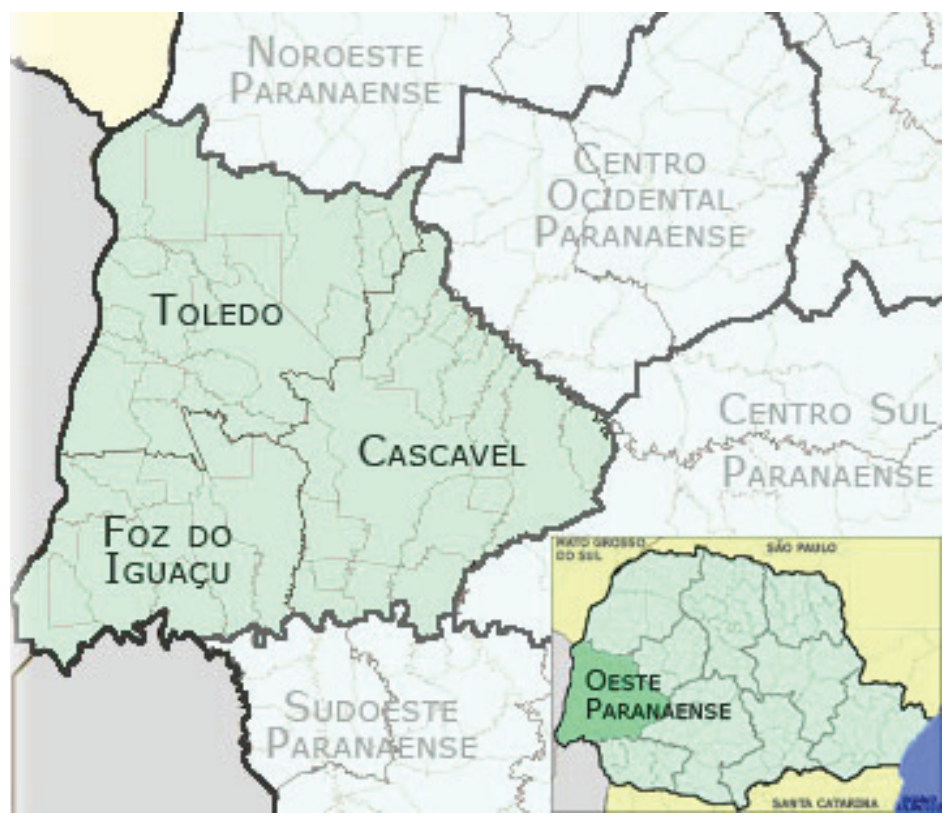

Figura 1: Mapa da região Oeste do Paraná Fonte: Oparana (2012).

A 'marcha para o oeste' foi uma campanha de forte apelo nos meios de comunicação, produção cultural e educação no Brasil no decorrer da década de 1930. Com a busca da exaltação do sentimento da brasilidade e o resgate do valor do 'sertão', o povo brasileiro deveria voltar 
antes explorado pelos bandeirantes e depois permanentemente esquecido. Nessa campanha "estava embutido o desejo de fazer as pessoas circularem para o Oeste, a fim de que todos, de uma forma ou de outra, estivessem presentes no grande todo" (WACHOWICZ, 1988, p. 15). No âmbito paranaense, a campanha da 'marcha para o oeste' contribuiu, sobretudo, para atingir o que a bibliografia e documentos da época consideravam 'sertão'. Ignorando as populações tradicionais que residiam nesses locais, o discurso oficial perpetuou a visão de que esse movimento colaborou na ocupação de uma região 'vazia', 'isolada', praticamente abandonada, entregue à ação das obrages estrangeiras.

Desde a independência política da província do Paraná em 1853, os governos do Estado tornaram-se responsáveis pela distribuição das terras tidas como devolutas e sempre o fizeram, beneficiando as grandes empresas colonizadoras, numa espécie de troca de benefícios. Os caboclos pioneiros, ou pequenos proprietários, ocupantes e interessados na posse de terras sempre foram deixados para segundo plano. As grandes empresas representavam, acima de tudo, o interesse do capital e detinham prioridade para demarcar e revender as terras.

Desde o final do século XIX e início do século XX, o governo fez enormes concessões a empresas estrangeiras tendo como objetivo a exploração de erva-mate, madeira e a colonização da região Oeste. Essas empresas, já anteriormente citadas, eram denominadas obrages e os seus trabalhadores eram os mensus', geralmente paraguaios, argentinos e 'guaranis modernos' - termo empregado aos índios guaranis miscigenados no Paraguai.

O obragero, como era conhecido o proprietário de latifúndio argentino, geralmente tinha conhecimento de que suas embarcações poderiam navegar até as sete quedas do rio Paraná. Diante dessa possibilidade, organizava uma empresa, montava uma expedição e, em alguns casos, comprava terras do governo paranaense. No entanto, era mais comum o ingresso dos obrageros em território paranaense por vias ilegais.

\footnotetext{
7 A expressão vem do espanhol, da palavra 'mensual', ou seja, mensalista (GREGORY, 2002, p. 89).
} 
Vários peões - os mensus - seguiam a expedição, munidos de produtos de primeira necessidade e instrumentos para a colheita da erva-mate, que era nativa na região. Na maioria das vezes, os mensus saíam dos navios e se fixavam nas margens fluviais dos rios da região. Fixavam-se nesses locais, formando um povoado, mais conhecido como 'porto', por onde eram escoadas a produção da erva-mate e, posteriormente, a da madeira. Por toda essa região de fronteira, multiplicaram-se os denominados 'portos', que surgiram com o estabelecimento das obrages e a fixação dos mensus. Como afirma Ruy Wachowicz, "esta frente extrativa de erva-mate era, pois, de capital argentino, mão de obra paraguaia e matéria prima brasileira" (1988, p. 27).

O desenvolvimento das Obrages foi facilitado porque o governo imperial em meados do século XVIII havia assinado um acordo de navegação com a Argentina e com o Paraguai. Esse documento garantiu o acesso à província do Mato Grosso com entrada pela foz do rio da Prata até o rio Paraná. Na outra parte do acordo a Argentina tinha assegurado o direito de navegar pelo rio da Prata, desde o Iguaçu até a distância das Sete Quedas. Essas resoluções tornaram propícia a atividade de contrabando da erva-mate, muito consumida pela população platina, e da madeira, que, além de utilizada pelos argentinos, era também exportada para o Canadá e Estados Unidos (COLODEL, 2008).

Na década de 1920, o Oeste paranaense era uma fronteira que praticamente não pertencia ao Brasil. Falava-se pouco a língua portuguesa e circulava como moeda o peso argentino. As obrages justificavam a existência de mais de dez mil habitantes no Oeste paranaense na década de 1930, a maioria de origem platina. Era uma região de difícil acesso, onde a penetração realizava-se apenas por meio do rio Paraná, da estrada de ferro Guaíra-Porto Mendes e da 'estrada' que levava de Guarapuava a Foz do Iguaçu (STECA; FLORES, 2008). No entanto, os meios de transporte eram todos controlados pela Argentina e pela Companhia Mate Laranjeira, de origem paraguaia. 
Mesmo com sucessivas tentativas de intervenção do governo estadual e do federal, as obrages impediam e dificultavam a criação de colônias de povoamento. Os argentinos e os seus vapores eram os principais causadores do isolamento a que estavam condenados os moradores de Foz do Iguaçu. O acordo que havia sido selado estimulou o desenvolvimento das obrages e o monopólio do comércio e da navegação pelo rio Paraná. Por outro lado, esse sistema proporcionou a elevação do desmatamento e esgotamento das reservas naturais, além de incentivar o regime de trabalho semiescravista.

A expedição chefiada pelo Secretário do Estado do Paraná, Pietro Cezar Martinez, e o Tenente-coronel José de Lima Figueiredo para o reconhecimento do extremo Oeste do Paraná em 1936, descreveu os aspectos da região, ressaltando a inexistência de brasileiros no local:

Atravessamos o rio Ocobi, que se deveria grafar 'Oco-u', pois oco é um nome de um pássaro raro, aquático e 'u', significa água, em guarani. Escolhemos parar na obrage Sete de Setembro, do Senhor Eugenio Caferata, argentino. O senhor Caferata trabalha com 120 homens, sendo 82 paraguaios e 38 argentinos. O único brasileiro existente nesse recanto do nosso Brasil é um soldado de polícia ali destacado, que, aliás, é casado com uma paraguaia e seus filhos falam [...] o guarani (MYSKIW, 2002, p. 64).

$\mathrm{Na}$ época da expedição os limites territoriais já estavam definidos. Mas a integração econômica e cultural era ideal a ser alcançado (FREITAG, 2007). A situação de miséria e abandono na região aos poucos foi sendo denunciada. Essas revelações alcançaram grande projeção em Curitiba e no Rio de Janeiro, durante o período da República Velha. Até em 1924, com a passagem da Coluna Prestes pelo Oeste paranaense, os tenentes rebeldes ficaram chocados com as cenas que viam, principalmente quanto à desnacionalização da fronteira e as relações de exploração estabelecidas pelas empresas estrangeiras (DIAS; PRIORI, 2009). O governo paranaense desarticulou finalmente as obrages, ao baixar o decreto de $\mathrm{n}^{\circ} 300 \mathrm{em}$ 03, de novembro de 1930. Com essa ação fez voltar ao poder estadual as 
concessões cedidas a empresas estrangeiras e nacionais que não haviam cumprido com as cláusulas contratuais. Além da desarticulação oficial, a exploração obrageira já vinha passando por graves crises econômicas em detrimento da desvalorização do mate brasileiro no mercado argentino.

Efetivado o cancelamento das concessões, o Estado baixou o decreto $n^{\circ} 800$, em 08 de agosto de 1931, e a lei n 46 em 10 de dezembro de 1935. Por meio desses atos jurídicos, passou a vender as terras devolutas recuperadas para empresas ou particulares. A partir desse momento, iniciaram-se duas frentes de colonização da região Oeste: a frente pública, da qual o Estado se encarregava de fazer o loteamento, e a frente privada, a cargo de empresas de colonização e imobiliárias.

Os projetos de colonização pela iniciativa privada foram mais eficientes do que os projetos da iniciativa do Estado. Isso pode ser explicado pela experiência das empresas no ramo. Geralmente essas empresas conheciam quais as melhores técnicas a serem utilizadas tanto para um bom desenvolvimento econômico da área a ser colonizada, como para aumentar seus lucros. Dentre as empresas que atuaram no Oeste do Estado merecem destaque as companhias Industrial Madeira e Colonizadora Rio Paraná Ltda (Maripá); Pinho e Terras Ltda; Industrial Agrícola Bento Gonçalves; Colonizadora Gaúcha Ltda.; Colonizadora Matelândia; Colonizadora Criciúma; Sociedade Colonizadora União D’Oeste Ltda; e Colonizadora Norte do Paraná.

Essas empresas, juntamente com outras de menor relevância, colonizaram uma área superior a dois milhões de hectares. Ao firmarem o acordo com o Estado, deveriam se dedicar às atividades relacionadas à madeira, à indústria, ao comércio e à venda das terras. Dentre elas, a Maripá foi a que obteve maior destaque por ações sociais, empreendendo construções de casas, hotéis e estradas, não atuando apenas e exclusivamente na venda de lotes de terras.

A venda de lotes, tanto urbanos como rurais, ocorria de forma planejada, como podemos constatar no relatório da empresa Pinho e Terras Ltda, citado por Myskiw: 
Os lotes coloniais, medindo em torno de 25 hectares, formariam perímetros de área diferentes de acordo com o relevo e a hidrografia. Ao redor dos núcleos populacionais foram criados lotes de 2,5 hectares, chácaras destinadas ao cultivo de hortigranjeiros. Internamente, os núcleos populacionais urbanos (vilas e cidades) seriam divididos em quarteirões, medindo geralmente $100 \times 100$ metros, ou seja, 10.000 metros quadrados (um hectare), contando cada quarteirão com 10 lotes de 100 metros quadrados (MYSKIW, 2002, p. 67).

A Maripá fixou sede em Toledo e tomou uma série de medidas para formar diversas colônias de agricultores na região. Privilegiou a venda das terras em pequenas propriedades, com tamanho aproximado entre 10 alq. (24 ha). A companhia colonizadora dividiu as terras de modo que cada propriedade tivesse um curso de água. Os compradores eram selecionados rigorosamente. Chama a atenção que a venda desses lotes era feita de preferência para gaúchos e catarinenses, em sua maioria com descendência alemã ou italiana. Em 1951 já se podia notar a presença de algumas famílias na localidade de General Rondon (atual Marechal Cândido Rondon) e em Toledo. Entre 1951 e 1954 foram fundadas vilas como Novo Sarandi, Quatro Pontes, Margarida, Vila Nova, Novo Três Passos, Mercedes, Nova Santa Rosa, Maripá, São Roque e São Petrogrado. Muitas dessas vilas ou colônias se tornaram municípios, enquanto outras se firmaram como distritos de Toledo ou Marechal Cândido Rondon.

No processo de colonização do Oeste do Paraná, destacou-se a ocupação majoritária por migrantes de origem italiana e alemã, originários dos Estados de Santa Catarina e Rio Grande do Sul. As condições favoráveis para o desenvolvimento da agricultura foi um fator de motivação para a ocupação da região. Isso ocorreu principalmente durante a Segunda Guerra Mundial (1930-1945), quando ficou evidente que alguns setores do país necessitavam ser ampliados, entre eles, a industrialização, a indústria de base e a criação de uma fronteira agrícola forte.

Numa perspectiva social, o Paraná possui um amplo histórico de conflitos que envolve a disputa por terras. Nas regiões Sudoeste e Oeste 
do Paraná não foi diferente. Isso porque geralmente as terras doadas ou vendidas às colonizadoras estavam em sua maioria ocupadas por posseiros e essas empresas se encarregaram de expulsá-los. A Revolta de 1957 (AMANCIO, 2009) e os conflitos agrários na região Oeste (CRESTANI, 2010) são exemplos de como esse processo de colonização ocorreu no limiar entre o progresso e a violência.

A segurança de quem comprava a terra era explícita pelo contrato de compra e venda. No entanto, muitos litígios ocorreram na área, pelo fato de que muitas posses eram devolutas, ou mesmo pela ação de grilagem e má fé das empresas colonizadoras (WESTPHALEN; MACHADO; BALHANA, 1988). Muitos pesquisadores afirmam que a Maripá teria sido a única colonizadora da região a garantir tranquilidade e segurança depois da devida compra dos lotes. Uma explicação provável seria o fato de que essa empresa teria comprado a sua gleba de terras, em 1946, da antiga Fazenda Britânica, cujo ex-proprietário, a Companhia de Madeiras Del Alto Paraná, havia efetuado a compra diretamente numa transação legalizada com o Estado do Paraná. A partir do início da década de 1950, começou a chegar à área um grande número de colonos do Rio Grande do Sul, Santa Catarina e do Sudoeste paranaense. Com uma pequena quantia em dinheiro, essas pessoas compravam o 'direito de posse' dos primeiros posseiros ou de supostos agentes do Instituto Nacional de Imigração e Colonização. Iniciou-se um ciclo acelerado de compra e venda de posses, que muitas vezes se dava por escambo: "Dez alqueires de terra chegaram valer uma espingarda calibre 32 e uma novilha" (COLOMBO, 2001, p. 14).

\section{Conflitos pela terra}

Vários historiadores (MYSKIW, 2002; CRESTANI, 2010) afirmam que a atuação de empresas privadas na colonização da região Oeste do Paraná ocorreu entre os anos de 1950 e 1960. O processo colonizador dessa área envolveu tanto as companhias colonizadoras, 
como os jagunços, posseiros, colonos e grileiros que, em muitos casos, utilizaram-se da violência física ou moral para se apossarem da terra ou defenderem suas propriedades, ou o que consideravam serem os seus domínios.

A disputa pela posse de terras na região e que envolveu a União, empresas colonizadoras e o Estado do Paraná é resultado do impasse pela posse da terra proveniente desde a colonização do Brasil. Embora a confusão em torno da documentação fosse notada desde a época das 'sesmarias' (sistema de doação de terras promovido por Portugal no século XVI), o tumulto ficou mais evidente após a implantação da Lei de Terras de 1850. Este instrumento jurídico procurou definir o que eram terras devolutas e objetivava diferenciar as terras públicas das privadas, impedindo, ainda, o acesso à terra devoluta, a não ser por meio da compra (MOTTA, 2005).

No Paraná, o período considerado mais turbulento e que envolveu disputas por terras ocorreu necessariamente durante os governos de Moysés Lupion (1947-1951 e 1956-1961). No que diz respeito à região Oeste do Estado, o momento mais delicado foi durante os anos de 1957 a 1960, quando Lupion emitiu uma série de títulos em relação à mesma área (CRESTANI, 2010). Como consequência, iniciou-se uma disputa judicial acirrada pelas terras que perdurou muitos anos, a ponto de os próprios funcionários do Instituto Nacional de Colonização e Reforma Agrária (INCRA) de Cascavel reclamar do cansaço "de tentar decidir sobre os herdeiros da terra [...]. Quando não é posseiro que aparece aqui com uma escritura na mão é a própria pessoas que, dizendo-se herdeiro de um pedaço de terra, vem atrás de nossas ajuda para poder ocupá-la" (JORNAL ESTADO DO PARANÁ, 1978, p. 24).

Os inúmeros títulos de terra emitidos por Moysés Lupion, além de duvidosos, muitas vezes estavam nas mãos de pessoas que residiam em outros Estados. Muitos, inclusive, portavam títulos em branco, o que indica como a distribuição desses documentos foi feita à revelia. Diante da forma desordenada de titulação das terras e acobertamento do poder 
político, podemos compreender o surgimento dos conflitos agrários na região Oeste do Paraná.

Considerada a última fronteira agrícola do Paraná, a região Oeste despertava o interesse das companhias colonizadoras, a ponto de várias dessas empresas atuarem nessa área. Em virtude da diversidade de companhias colonizadoras que aí se estabeleceram e, embora os processos de disputa pela terra tenham semelhanças nos diferentes municípios que se formaram nessa região, é importante estarmos atentos para as particularidades desses litígios.

Assim, foram registrados desentendimentos pela posse da terra nos anos de 1950 na região que compreende os atuais municípios de Assis Chateaubriand e Tupãssi, quando os títulos da propriedade de terras dessa área foram concedidos por Moysés Lupion para a Colonizadora Norte do Paraná. Com base nesses documentos (os títulos), esta empresa colonizadora providenciou a desocupação imediata das propriedades rurais na região Oeste do Estado. Nessa área, a Companhia Colonizadora Norte do Paraná não economizou no uso de jagunços para expulsar e intimidar, inclusive com ameaças de morte, as pessoas que até então viviam nessas terras (CRESTANI, 2010).

Também não podemos nos esquecer da Revolta do Sudoeste de 1957, conflito marcado pela disputa de terras entre posseiros e a empresa colonizadora Clevelândia Industrial e Territorial Ltda (CITLA) e que se estendeu por uma área que compreende os atuais municípios de Capanema, Dois Vizinhos, Francisco Beltrão, Pato Branco, Santo Antônio do Sudoeste, Pranchita, Verê. Diferente das demais revoltas que ocorreram no Oeste do Paraná, a Revolta de 1957 foi concluída com a vitória dos posseiros, os quais tiveram suas posses reguladas e tituladas a partir de 1962 (AMANCIO, 2009).

Também nas localidades de Jardinópolis e Flor da Serra, interior do atual município de Medianeira, houve conflitos que envolveram a posse da terra. A revolta de posseiros que alcançou maior repercussão nessa área ocorreu em 1961, marcando os desentendimentos desses com as empresas 
colonizadoras Alto do Paraná, a Industrial Bento Gonçalves e Matelândia, que, segundo os títulos emitidos por Lupion, garantiram a posse das terras dessa região (COLOMBO, 2001).

Outro levante de posseiros ocorreu em Três Barras em agosto de 1964. Embora se trate de um movimento pouco estudado pela historiografia, também notamos as divergências em relação à posse das terras. $\mathrm{O}$ choque incluiu colonos, posseiros e supostos proprietários e envolveu políticos e a comunidade local. Além desses, existem registros de conflitos semelhantes ocorridos em Guaraniaçu e Guaíra, respectivamente, nos anos de 1955 e 1956.

Diante da miríade de conflitos que envolve a posse de terras, podemos dizer que a colonização do Oeste do Paraná ocorreu de forma 'irregular'. A 'propriedade', 'posse' e ‘titulação' se tornaram questões importantes para a efetiva colonização dessa região. Tamanho interesse por terras no Paraná ocorreu num momento em que a questão agrária, principalmente da reforma agrária, estava no centro de uma discussão nacional. Havia o desejo dos posseiros de permanecerem na terra, os interesses maiores das empresas colonizadoras, a questão da ilegalidade da terra ocupada e também o direito de quem já havia pagado pela sua terra, além das disputas nos tribunais estaduais e federais em torno das denominadas terras devolutas. Todos esses interesses, muito contraditórios, se chocavam e acabavam inevitavelmente gerando conflitos, muitas vezes intensos e violentos.

Apesar desses problemas e litígios ocorridos que envolviam a questão da luta pela terra, podemos dizer que houve êxito nas ações das empresas colonizadoras. Se levarmos em consideração o trabalho final, é possível observar o aumento e desenvolvimento da população e de sua infraestrutura regional ocorrida com o passar de alguns anos após as ocupações imobiliárias. As companhias, apesar de múltiplas e variadas, delinearam a organização do espaço, estipulando o tamanho das propriedades rurais e o traçado das cidades. Também a cultura local 
foi influenciada com a fixação de migrantes oriundos de outros Estados, como Rio Grande do Sul e Santa Catarina.

No entanto, famílias inteiras de posseiros foram expulsas de suas terras para dar espaço à iniciativa privada. É inevitável analisar essas lutas sem nos depararmos com o cotidiano das pessoas que viviam nessa área. Muitos deixaram sua terra natal na perspectiva de construir uma vida familiar mais próspera e se estabilizar com uma pequena propriedade rural. No entanto, se surpreenderam com a ganância pela posse da terra. Enquanto que as visões das companhias colonizadoras e de representantes do poder político estão expressas em discursos que justificam as suas ações em prol do desenvolvimento da região, a ótica das pessoas comuns pode ser buscada na memória social da população do Oeste do Paraná. Muitas vezes, um imaginário que ainda carrega as marcas do poder e violência a que foram submetidos. Por isso, ao falarmos da colonização do Oeste do Paraná, é importante lidarmos com as múltiplas interpretações que esse tema nos fornece, por mais que a história oficial tente apagá-las.

\section{Referências}

AMANCIO. S. M. Ontem, luta pela terra; hoje, monumento histórico: a revolta dos posseiros no Sudoeste do Paraná em suas variadas versões. 2009. 178 f. Dissertação (Mestrado em História) - Universidade Estadual de Maringá, Maringá, 2009.

COLODEL, J. A. Cinco séculos de história. In: PERIS, A. F. (Org.). Estratégias de desenvolvimento regional: região oeste do Paraná. Cascavel: Edunioeste, 2008. p. 29-75.

COLOMBO. O. L. Memória, documentos sobre a Revolta de 61. Serranópolis do Iguaçu: Igal, 2001.

CRESTANI, L. A. Memórias dos conflitos agrários na região Oeste do Paraná (1950-1980). 2010. 67 f. Monografia (Especialização em História e Humanidades)-Universidade Estadual de Maringá, Maringá, 2010.

DIAS, E. S.; PRIORI, A. Fronteira sitiada: as memórias dos moradores de Foz do Iguaçu sobre os movimentos tenentistas (1924-1925). In: PRIORI, A. (Org.). História, memória e patrimônio. Maringá: Eduem, 2009. p. 49-64. 
FREITAG, L. da C. Extremo-oeste paranaense: história territorial, região, identidade e (re) ocupação. 2007. 209 f. Tese (Doutorado em História) - Universidade Estadual Paulista, Franca, 2007.

GREGORY. V. Os eurobrasileiros e o espaço colonial: migrações no Oeste do Paraná (19401970). Cascavel: Edunioeste, 2002.

JORNAL O ESTADO DO PARANÁ, Curitiba, 04 fev. 1978.

MARTINS, W. Um Brasil diferente: ensaio sobre fenômenos de aculturação no Paraná. 2. ed. São Paulo: T. A. Queiroz, 1989.

MOTA, L. T. História do Paraná: ocupação humana e relações interculturais. Maringá: Eduem, 2005.

MOTTA, M. M. M. Dicionário da terra. Rio de Janeiro: Civilização Brasileira, 2005.

MYSKIW. A. M. Colonos, posseiros e grileiros: conflitos de terra no oeste paranaense (1961-1966). 2002. 201 f. Dissertação (Mestrado em História) - Universidade Federal Fluminense, Niterói, 2002.

NADALIN, S. O. Paraná: ocupação do território, população e migrações. Curitiba: SEED, 2001.

OPARANA.COM. Disponível em: < http://www.oparana.com>. Acesso em: 06 jan. 2012.

STECA, L. C.; FLORES, M. D. História do Paraná: do século XVI à década de 1950. Londrina: UEL, 2008.

WACHOWICZ, R. C. História do Paraná. Curitiba: Vicentina, 1988.

WACHOWICZ, R. C. Obrageiros, mensus e colonos. 2. ed. Curitiba: Vicentina, 1987.

WESTPHALEN, C.; MACHADO, B. P.; BALHANA, A. P. Ocupação do Paraná. Cadernos de Migração, São Paulo, v. 3, p. 4-43, 1988. 